\section{(1)}

CrossMark

\title{
Potential of nintedanib in treatment of progressive fibrosing interstitial lung diseases
}

\author{
Lutz Wollin ${ }^{1}$, Jörg H.W. Distler², Elizabeth F. Redente ${ }^{3}$, David W.H. Riches ${ }^{3,4}$, \\ Susanne Stowasser ${ }^{5}$, Rozsa Schlenker-Herceg ${ }^{6}$, Toby M. Maher ${ }^{7,8}$ and \\ Martin Kolb (1)
}

Affiliations: ${ }^{1}$ Boehringer Ingelheim Pharma GmbH \& Co. KG, Biberach, Germany. ${ }^{2}$ Dept of Internal Medicine 3 Rheumatology and Immunology, Friedrich-Alexander University Erlangen-Nürnberg (FAU) and University Hospital Erlangen, Erlangen, Germany. ${ }^{3}$ Program in Cell Biology, Dept of Pediatrics, National Jewish Health, Denver, CO, USA. ${ }^{4}$ University of Colorado School of Medicine, Aurora, CO, USA. ${ }^{5}$ Boehringer Ingelheim International $\mathrm{GmbH}$, Ingelheim, Germany. ${ }^{6}$ Boehringer Ingelheim Pharmaceuticals, Inc., Ridgefield, CT, USA. ${ }^{7}$ National Heart and Lung Institute, Imperial College London, London, UK. ${ }^{8}$ National Institute for Health Research Clinical Research Facility, Royal Brompton Hospital, London, UK. ${ }^{9}$ Dept of Respiratory Medicine, Pathology and Molecular Medicine, McMaster University and St Joseph's Healthcare, Hamilton, ON, Canada.

Correspondence: Lutz Wollin, Boehringer Ingelheim Pharma GmbH \& Co. KG, Birkendorfer Strasse 65, 88397 Biberach an der Riss, Germany. E-mail: stefan-lutz.wollinaboehringer-ingelheim.com

@ERSpublications

Nonclinical studies suggest that nintedanib, an approved treatment for idiopathic pulmonary fibrosis, may have anti-fibrotic effects in other interstitial lung diseases with a progressive fibrosing phenotype http://bit.ly/2NiCAYx

Cite this article as: Wollin L, Distler JHW, Redente EF, et al. Potential of nintedanib in treatment of progressive fibrosing interstitial lung diseases. Eur Respir J 2019; 54: 1900161 [https://doi.org/10.1183/ 13993003.00161-2019].

ABSTRACT A proportion of patients with fibrosing interstitial lung diseases (ILDs) develop a progressive phenotype characterised by decline in lung function, worsening quality of life and early mortality. Other than idiopathic pulmonary fibrosis (IPF), there are no approved drugs for fibrosing ILDs and a poor evidence base to support current treatments. Fibrosing ILDs with a progressive phenotype show commonalities in clinical behaviour and in the pathogenic mechanisms that drive disease worsening. Nintedanib is an intracellular inhibitor of tyrosine kinases that has been approved for treatment of IPF and has recently been shown to reduce the rate of lung function decline in patients with ILD associated with systemic sclerosis (SSc-ILD). In vitro data demonstrate that nintedanib inhibits several steps in the initiation and progression of lung fibrosis, including the release of pro-inflammatory and pro-fibrotic mediators, migration and differentiation of fibrocytes and fibroblasts, and deposition of extracellular matrix. Nintedanib also inhibits the proliferation of vascular cells. Studies in animal models with features of fibrosing ILDs such as IPF, SSc-ILD, rheumatoid arthritis-ILD, hypersensitivity pneumonitis and silicosis demonstrate that nintedanib has anti-fibrotic activity irrespective of the trigger for the lung pathology. This suggests that nintedanib inhibits fundamental processes in the pathogenesis of fibrosis. A trial of nintedanib in patients with progressive fibrosing ILDs other than IPF (INBUILD) will report results in 2019. 


\section{Introduction}

Interstitial lung diseases (ILDs) comprise a large and varied group of diseases that generally affect the interstitium, the connective tissue stroma that separates the epithelial and endothelial barriers in the lungs. ILDs may have a known cause, e.g. they may be a manifestation of an autoimmune disease or a result of sensitisation to an inhaled antigen. However, ILDs also include several diseases of unknown cause [1]. Idiopathic pulmonary fibrosis (IPF) is one of the most common types of ILD. Although the course of IPF is variable, IPF is, by definition, a progressive fibrosing disease that ultimately results in respiratory failure [2]. A proportion of patients with certain other types of ILD also develop a progressive fibrosing phenotype associated with decline in lung function, worsening symptoms and quality of life, and early mortality [3]. These include idiopathic nonspecific interstitial pneumonia [4], ILDs associated with autoimmune diseases such as rheumatoid arthritis (RA-ILD) [5] and systemic sclerosis (SSc-ILD) [6], chronic hypersensitivity pneumonitis [7], chronic sarcoidosis [8], exposure-related ILDs such as silicosis [9], and unclassifiable idiopathic interstitial pneumonia [10]. At present, the goal of treatment for fibrosing ILDs with a progressive phenotype is to slow the decline in lung function. However, IPF is the only form of fibrosing ILD for which approved drug therapies are available. The treatment of patients with other types of progressive fibrosing ILD is based largely on immunosuppression, which, other than in SSc-ILD, is not supported by a robust evidence base, leaving patients with a high unmet need for efficacious treatment options $[11,12]$.

\section{Pathogenesis of fibrosing ILDs with progressive phenotype}

Several mechanisms are known to be involved in the pathogenesis and progression of all fibrosing ILDs (figure 1). All ILDs are believed to be triggered by repetitive chronic epithelial or vascular injuries, or by granulomatous inflammation, which lead to cell destruction and, in the case of fibrotic disease, to unregulated repair [13-15]. Fibroblasts, the main effector cells in fibrosing ILDs, are drawn from different sources to the site of injury. Resident interstitial fibroblasts proliferate and migrate [16], fibrocytes from

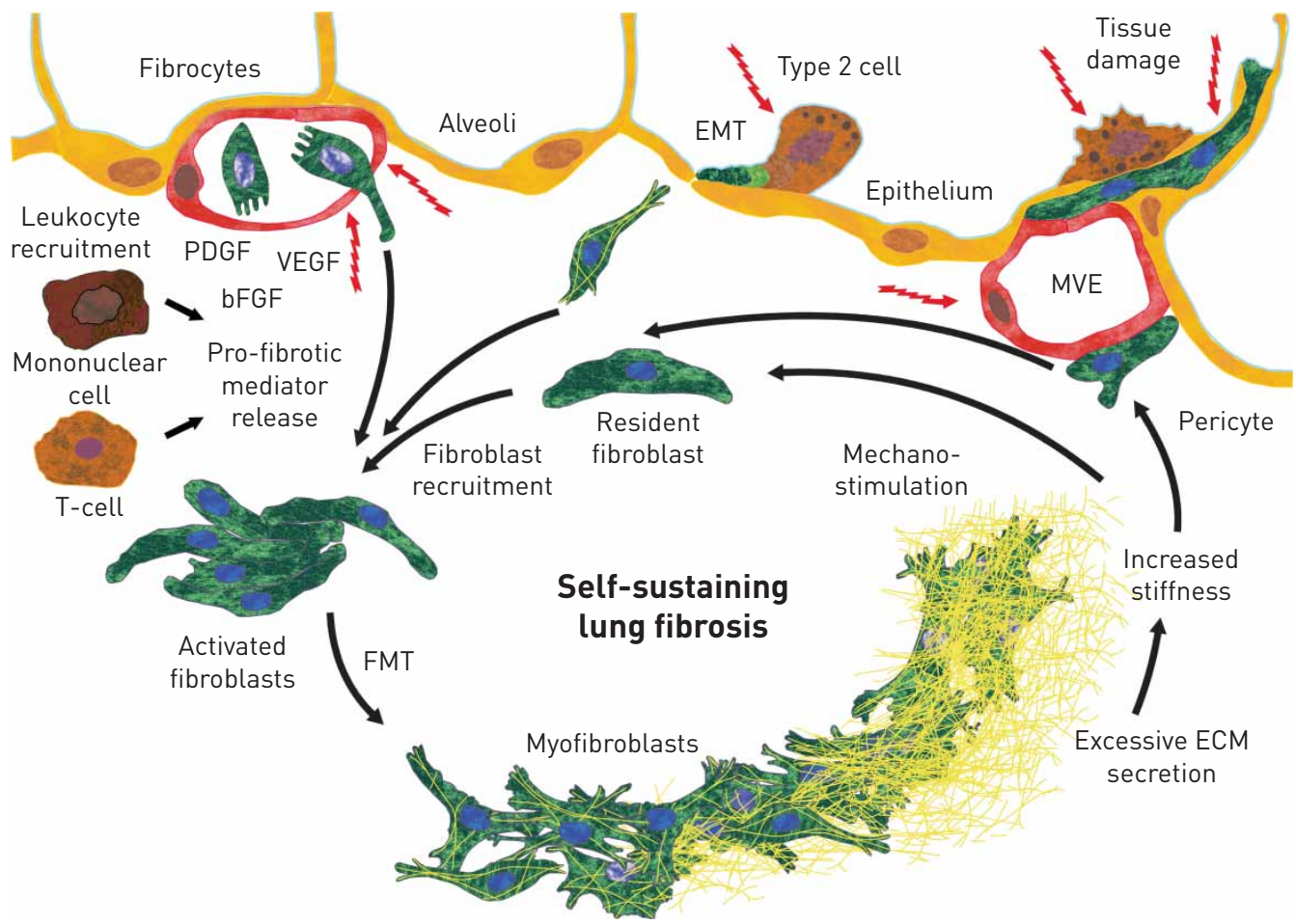

FIGURE 1 Mechanisms known to be involved in the pathogenesis and progression of fibrosing interstitial lung diseases. EMT: epithelial-mesenchymal transition; PDGF: platelet-derived growth factor; VEGF: vascular endothelial growth factor; bFGF: basic fibroblast growth factor; MVE: microvascular epithelium; FMT: fibroblast-myofibroblast transition; ECM: extracellular matrix. Tissue damage may occur at the alveolar epithelial and/or microvascular endothelial sites. Fibroblasts are recruited from resident fibroblasts, circulating fibrocytes, and epithelial cells and fibrocytes undergoing EMT. Growth factors are released by the damaged epithelium and endothelium, and leukocytes are recruited. Mononuclear cells and T-cells release pro-fibrotic mediators. Activated fibroblasts transition to myofibroblasts (FMT), which release excessive amounts of ECM. This results in increased tissue stiffness, which further stimulates fibroblast activation, leading to self-sustaining fibrosis. 
the circulation invade [17], and epithelial cells [18] and pericytes [19] acquire features usually associated with fibroblasts. Ultimately, these fibroblasts are activated to become myofibroblasts, which secrete excessive amounts of extracellular matrix, resulting in increased tissue stiffness and loss of function of the alveolar tissue [20]. In addition, macrophages and lymphocytes are recruited to the site of injury and release pro-fibrotic mediators that further promote fibroblast activation [16]. In a feed-forward loop, the increased lung tissue stiffness further activates and stimulates fibroblasts, in a process known as mechano-stimulation, to drive self-sustaining and progressive lung fibrosis [21].

\section{Nintedanib}

Nintedanib has been approved for the treatment of IPF in many countries, including Europe and the USA. The standard dosing in adults is $150 \mathrm{mg}$ twice daily. Maximum plasma concentration at steady state after standard oral dosing in patients with IPF is $\sim 59-74 \mathrm{nmol} \cdot \mathrm{L}^{-1}[22,23]$.

Nintedanib is a small-molecule tyrosine kinase inhibitor that targets platelet-derived growth factor (PDGF) receptor- $\alpha$ and $-\beta$, fibroblast growth factor (FGF) receptor-1-3 and vascular endothelial growth factor (VEGF) receptor-1-3 [24]. Nintedanib binds competitively to the ATP-binding pocket of these receptors, thereby blocking intracellular signalling [24]. Nintedanib also inhibits the Src family kinase lymphocyte-specific tyrosine protein kinase (Lck), colony-stimulating factor (CSF)-1 receptor (CSF1R) and 20 other kinases with median inhibitory concentration (IC50) values $<100 \mathrm{nM}$ [24, 25]. The impact of enzymatic inhibition of most of these kinases on cellular functions has not yet been explored.

\section{Mechanisms of action of nintedanib in pulmonary fibrosis}

In vitro data have demonstrated that nintedanib inhibits a number of steps in the initiation and progression of lung fibrosis that might have relevance to the treatment of patients with progressive fibrosing ILDs.

Nintedanib exerts anti-inflammatory activity, attenuating the initiation and progression of fibrosis On activation, T-cells release pro-inflammatory and pro-fibrotic mediators that are believed to initiate and enhance the progression of fibrosis in autoimmune diseases [26, 27]. Lck is activated after T-cell stimulation, and is required for T-cell proliferation and interleukin (IL)-2 production [28-31]. At an enzymatic level, nintedanib inhibits the activity of Lck with an IC50 of $16 \mathrm{nM}$ [24]. In addition, nintedanib inhibits the release of mediators including IL-2, IL-4, IL-5, IL-10, IL-12p70, IL-13 and interferon- $\gamma$ by human peripheral blood mononuclear cells or T-cells [32]. The potency of nintedanib is within the range of exposure observed in patients with IPF treated with the standard dose of $150 \mathrm{mg}$ twice daily, suggesting that it is feasible that treatment with nintedanib would modulate these mediators during clinical use of the drug.

CCL18, a marker of M2 macrophage polarisation, has been associated with disease progression in patients with fibrosing ILDs, including IPF, SSc and RA [33-36]. It has been demonstrated that nintedanib prevents pro-fibrotic macrophage polarisation. When macrophages differentiated from human THP-1 cells exposed to a cocktail of IL-4/IL-13 or IL-4/IL-13 and IL-6 were treated with nintedanib at a concentration of $100 \mathrm{nM}$, the release of CCL18 was significantly reduced [37]. It is assumed that the inhibitory activity of nintedanib on CSF1R, which has been demonstrated at an enzymatic level with an $\mathrm{IC}_{50}$ of $5 \mathrm{nM}$ [25], is at least partly responsible for this reduction. A recent study showed that nintedanib $(0.01-1 \mu \mathrm{M})$ prevented the CSF1-induced phosphorylation of CSF1R, with a significant decrease in production of CCL2, adhesion of macrophages and polarisation of macrophages to alternative M2a macrophages [38]. Nintedanib has also been shown to inhibit alternative activation of monocytes. At a concentration of $100 \mathrm{nM}$, nintedanib significantly reduced M2 polarisation of human macrophages incubated with macrophage CSF, IL-4 and IL-13, as shown by changes in the mean fluorescence intensity of CD163 and CD206, while expression of M1 markers did not change [39].

\section{Nintedanib inhibits fundamental processes of progressive lung fibrosis}

Fibrocytes are a source of lung fibroblasts in fibrosing ILDs and are believed to promote fibrosis [40]. Nintedanib has been shown to attenuate the migration of fibrocytes, their differentiation to fibroblasts and the triggering of fibroblast proliferation by cultured fibrocytes [41]. Activated interstitial fibroblasts are the key effector cells in the pathogenesis of fibrosing ILDs. Nintedanib inhibits fibroblast proliferation induced by stimuli such as PDGF, FGF, VEGF [42, 43] and serum [44]. Nintedanib has also been shown to reduce the motility of lung fibroblasts from patients with IPF [45] and to inhibit the contraction of human lung fibroblasts in collagen gels stimulated with PDGF [46]. These effects are not limited to the lung: studies conducted on dermal fibroblasts from patients with SSc showed that nintedanib reduced their PDGF- and transforming growth factor (TGF)- $\beta$-induced proliferation and migration [47]. 
Nintedanib inhibits TGF- $\beta$-induced fibroblast to myofibroblast transformation [48] and the release of collagen from TGF- $\beta$-stimulated lung fibroblasts [37]. Upon TGF- $\beta$ stimulation, pericytes, microvascular mural cells of mesenchymal origin, may achieve features of myofibroblasts and form fibroblastic foci. Nintedanib has been shown to inhibit deposition of fibronectin and collagen 1 by pericytes with myofibroblast features when they are cultured on decellularised lung matrix [49]. Furthermore, nintedanib reduces the enzymatic activity and secretion of matrix metalloproteinase (MMP)-2 and tissue inhibitor of MMP (TIMP)-2 by primary lung fibroblasts from patients with IPF [42], and increases MMP-8, MMP-9 and MMP-13 expression, and MMP-2 and MMP-9 activity, in pericytes activated with TGF- $\beta 1$ [49]. Outside the lung, nintedanib reduced myofibroblast differentiation and collagen release from dermal fibroblasts from patients with SSc [47].

\section{Nintedanib targets cells of the lung vasculature}

The potential impact of attenuating vascular remodelling in patients with IPF and other fibrosing ILDs remains controversial $[50,51]$. Nintedanib inhibits the proliferation of several vascular cell types in the lung, including endothelial cells, pericytes and smooth muscle cells $[24,52]$. Nintedanib also inhibits the proliferation of human pulmonary artery vascular smooth muscle cells at basal conditions and on stimulation with PDGF [39]. Taken together, the experimental evidence supports nintedanib having effects on vascular cells; however, whether these effects add to its anti-fibrotic activity remains to be elucidated.

\section{Studies of nintedanib in animal models of pulmonary fibrosis}

Nintedanib has been explored in several animal models with features of fibrosing ILDs, such as IPF, SSc-ILD, RA-ILD, chronic hypersensitivity pneumonitis and silicosis. In these animal models, nintedanib was administered in a therapeutic manner, i.e. after the onset of substantial fibrosis. Nintedanib demonstrated anti-fibrotic activity irrespective of the trigger that caused the fibrotic lung pathology, supporting the hypothesis that nintedanib inhibits fundamental processes in the pathogenesis of fibrosis. In addition to anti-fibrotic efficacy, nintedanib demonstrated anti-inflammatory activity and effects on the vascular compartment. In some animal models, nintedanib also showed effects on aspects of the disease other than fibrosing ILD, such as on heart fibrosis in a model of SSc-ILD, and on airway hyperreactivity and inflammation in a model showing features of chronic hypersensitivity pneumonitis. An overview of the different models is given in table 1 .

\section{Chemical trigger: bleomycin-induced lung fibrosis}

In rodents, intratracheal administration of bleomycin elicits severe epithelial damage, pulmonary inflammation, a massive fibrotic response in the lung and irregular vascularisation. In three animal models of bleomycin-induced lung fibrosis, nintedanib demonstrated anti-fibrotic, anti-inflammatory and vascular remodelling activity $[43,48,53]$. Anti-fibrotic activity was demonstrated through significant reductions in lung tissue density determined by micro computed tomography (CT), Ashcroft score, protein expression of TIMP-1, mRNA expression of TGF- $\beta 1$ and pro-collagen 1, and the collagen content of lung tissue, as well as by an improvement in lung function, as determined by static compliance calculated from pressurevolume loops. In addition, nintedanib showed anti-inflammatory activity, including attenuation of the accumulation of lymphocytes in bronchoalveolar lavage fluid (BALF) and a reduction in IL-1 $\beta$ and chemokine CXCL1/KC. In a mouse model of bleomycin-induced lung fibrosis, nintedanib normalised the distorted vascular architecture and inhibited proliferation of alveolar macrophages and alveolar epithelial type II cells [53].

\section{Environmental trigger: silica crystal-induced lung fibrosis}

Intratracheal application of silica crystals in mice results in ongoing lung inflammation and a progressive fibrotic response resembling features of silicosis. In this model, nintedanib reduced lung inflammation and granuloma formation and reduced neutrophil and lymphocyte numbers in the BALF, and IL-1 $\beta$, CXCL1/KC and IL-6 levels in lung tissue homogenates. Anti-fibrotic activity of nintedanib was demonstrated by a reduction in fibrosis in lung histology and reduced collagen levels in lung tissue [48].

\section{Allergic trigger: ovalbumin-induced fibrotic lung remodelling}

In mice, chronic allergic stimulation of the lung with ovalbumin results in features such as airway hyperreactivity, lung inflammation and goblet cell hyperplasia, and ultimately also in airway remodelling with fibrosis, resembling not only asthma, but also aspects of chronic hypersensitivity pneumonitis. In this model, treatment with nintedanib led to a significant reduction in airway hyperreactivity and a reduction in the hydroxyproline content of the lungs, indicating anti-fibrotic activity [54]. 
TABLE 1 Overview of nonclinical exploration of nintedanib in animal models of lung fibrosis

\begin{tabular}{|c|c|c|c|c|c|c|c|c|c|c|}
\hline & \multicolumn{2}{|c|}{$\begin{array}{l}\text { Bleomycin-induced lung fibrosis in } \\
\text { mice }[43,53]\end{array}$} & \multicolumn{2}{|c|}{$\begin{array}{l}\text { Bleomycin-induced lung } \\
\text { fibrosis in rats [43] }\end{array}$} & \multicolumn{2}{|c|}{$\begin{array}{l}\text { Silica-induced lung fibrosis in } \\
\text { mice [43] }\end{array}$} & $\begin{array}{l}\text { Chronic } \\
\text { allergen-induced } \\
\text { lung inflammation } \\
\text { and remodelling } \\
\text { in mice [54] }\end{array}$ & \multicolumn{2}{|c|}{$\begin{array}{l}\text { Rheumatoid arthritis and lung } \\
\text { fibrosis in SKG mice [55] }\end{array}$} & $\begin{array}{l}\text { Skin and lung } \\
\text { fibrosis in Fra-2 } \\
\text { mice [39] }\end{array}$ \\
\hline Trigger & \multicolumn{2}{|c|}{ Chemical: bleomycin } & \multicolumn{2}{|c|}{ Chemical: bleomycin } & \multicolumn{2}{|c|}{ Environmental: silica crystals } & $\begin{array}{l}\text { Allergic: } \\
\text { ovalbumin }\end{array}$ & \multicolumn{2}{|c|}{ Immunological: zymosan } & $\begin{array}{l}\text { Vascular: Fra-2 } \\
\text { transgene }\end{array}$ \\
\hline $\begin{array}{l}\text { Model } \\
\quad \text { characteristics }\end{array}$ & \multicolumn{2}{|c|}{$\begin{array}{l}\text { Epithelial cell injury-induced lung } \\
\text { inflammation and fibrosis }\end{array}$} & \multicolumn{2}{|c|}{$\begin{array}{l}\text { Epithelial cell injury-induced } \\
\text { lung inflammation and } \\
\text { fibrosis }\end{array}$} & \multicolumn{2}{|c|}{$\begin{array}{l}\text { Ongoing epithelial cell } \\
\text { injury-induced lung inflammation } \\
\text { and progressive fibrosis }\end{array}$} & $\begin{array}{l}\text { AHR, lung } \\
\text { inflammation and } \\
\text { remodelling with } \\
\text { goblet cell } \\
\text { hyperplasia, lung } \\
\text { fibrosis and ASM } \\
\text { hypertrophy }\end{array}$ & \multicolumn{2}{|c|}{$\begin{array}{l}\text { Resembles aspects of arthritic } \\
\text { joint inflammation and } \\
\text { progressive lung fibrosis }\end{array}$} & $\begin{array}{l}\text { Resembles } \\
\text { aspects of skin } \\
\text { and progressive } \\
\text { lung fibrosis in } \\
\text { SSc including } \\
\text { microvascular } \\
\text { disease and PH }\end{array}$ \\
\hline Treatment $^{\#}$ & $\begin{array}{l}\text { Preventive } \\
\text { days } 0-14\end{array}$ & $\begin{array}{l}\text { Therapeutic } \\
\text { days 7-21; } \\
\text { days 7-19 }\end{array}$ & $\begin{array}{l}\text { Preventive } \\
\text { days } 0-21\end{array}$ & $\begin{array}{l}\text { Therapeutic } \\
\text { days } 10-21\end{array}$ & $\begin{array}{l}\text { Preventive } \\
\text { days } 0-30\end{array}$ & $\begin{array}{l}\text { Therapeutic } \\
\text { days } 10-30^{\pi}\end{array}$ & $\begin{array}{l}\text { Chronic } \\
\text { starting at day } 35 \\
\text { for } 3 \text { months }\end{array}$ & $\begin{array}{l}\text { Early } \\
\text { weeks 5-11 }\end{array}$ & $\begin{array}{l}\text { Late } \\
\text { weeks } 10-16\end{array}$ & $\begin{array}{l}\text { Therapeutic } \\
\text { weeks } 10-16\end{array}$ \\
\hline $\begin{array}{l}\text { Effects of } \\
\text { nintedanib }\end{array}$ & $\begin{array}{l}\text { Lung fibrosis } \downarrow \text {; } \\
\text { lung } \\
\text { inflammation } \downarrow ; \\
\text { IL-1 } 1 \beta \downarrow ; \\
\text { TIMP-1 } 1 \text {; BALF } \\
\text { lymphocytes } \downarrow\end{array}$ & $\begin{array}{c}\text { Lung fibrosis } \downarrow ; \\
\text { Ashcroft score } \downarrow ; \\
\text { lung tissue } \\
\text { density } \downarrow ; \text { Cstat } \uparrow ; \\
\text { lung } \\
\text { inflammation } \downarrow ; \\
\text { lung collagen } \downarrow ; \\
\text { IL-1 } 1 \beta \downarrow ; \text { TIMP-1 } 1 \text {; } \\
\text { BALF } \\
\text { lymphocytes } \downarrow ; \\
\text { vascularisation } \downarrow\end{array}$ & $\begin{array}{l}\text { Ashcroft } \\
\text { score } \downarrow ; \\
\text { TGF- } \beta \\
\text { mRNA } \downarrow \text {; } \\
\text { pro-collagen } \\
1 \text { mRNA } \downarrow\end{array}$ & $\begin{array}{c}\text { Ashcroft } \\
\text { score } \downarrow ; \\
\text { TGF- } \beta \\
\text { mRNA } \downarrow \text {; } \\
\text { pro-collagen } \\
1 \text { mRNA } \downarrow\end{array}$ & $\begin{array}{l}\text { Lung fibrosis } \downarrow ; \\
\text { lung } \\
\text { inflammation } \downarrow ; \\
\text { lung collagen } \downarrow_{;} \\
\text {IL-1 } 1 \beta \downarrow ; \text { KC } \downarrow_{;} \\
\text {TIMP- } 1 \downarrow ; \text { BALF } \\
\text { neutrophils and } \\
\text { lymphocytes } \downarrow\end{array}$ & $\begin{array}{c}\text { Lung fibrosis } \downarrow ; \\
\text { lung } \\
\text { inflammation } \downarrow ; \\
\text { lung collagen } \downarrow ; \\
\text { IL-1 } 1 \beta \downarrow ; \text { IL- } 6 \downarrow ; \\
\text { KC } \downarrow ; \text { TIMP- } 1 \downarrow ; \\
\text { BALF } \\
\text { neutrophils and } \\
\text { lymphocytes } \downarrow\end{array}$ & 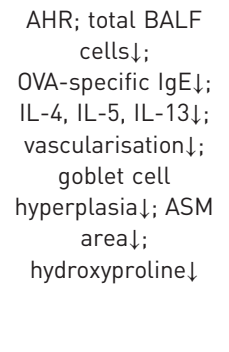 & $\begin{array}{c}\text { Arthritis } \\
\text { score } \downarrow ; \text { lung } \\
\text { tissue } B 220^{+} \\
\text {B-cells } \uparrow ; \\
\text { CD103 } \\
\text { dendritic } \\
\text { cells } \uparrow ; \\
\text { monocytes } \downarrow ; \\
\text { neutrophils } \uparrow\end{array}$ & $\begin{array}{l}\text { Hydroxyproline } \downarrow \text {; } \\
\text { BALF } \\
\text { lymphocytes and } \\
\text { neutrophils } \uparrow ; \\
\text { lung tissue } \\
\text { inflammatory } \\
\text { macrophages } \uparrow\end{array}$ & $\begin{array}{c}\text { Skin and lung } \\
\text { myofibroblasts } \downarrow ; \\
\text { dermal } \\
\text { thickness } \downarrow ; \\
\text { hydroxyproline } \downarrow ; \\
\text { ECM } \downarrow ; \text { vessel } \\
\text { wall thickness } \downarrow ; \\
\text { occluded } \\
\text { vessels } \downarrow ; \\
\text { VSMCs } \downarrow ; \text { MVEC } \\
\text { apoptosis } \uparrow\end{array}$ \\
\hline
\end{tabular}

$\downarrow$ : significant reduction (independent of dose); $\uparrow$ : significant increase (independent of dose). Fra-2: fos-related antigen-2; AHR: airway hyperreactivity; ASM: airway smooth muscle; SSc:

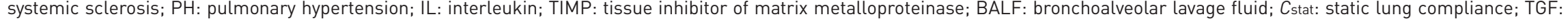
transforming growth factor; KC: chemokine CXCL1/KC; OVA: ovalbumin; ECM: extracellular matrix; VSMC: vascular smooth muscle cell; MVEC: microvascular endothelial cell. \#: "preventive" indicates that the administration of nintedanib started simultaneously with the pathogenic trigger and "therapeutic" indicates that the administration of nintedanib began after the onset of substantial fibrosis (the days/weeks listed indicate when nintedanib was administered relative to the pathogenic trigger); ${ }^{\text {: }}$ an effect of nintedanib was shown for treatment from day 10 to 30 (treatment only from day 20 to 30 was less effective). 
Immunological trigger: zymosan-induced arthritis and lung fibrosis in SKG mice

In SKG mice (which contain a Zap70 mutation resulting in autoreactive T-cells), administration of zymosan induces an arthritis pathology. The arthritis score increases for 6 weeks after zymosan administration, remains high up to week 10 and then slowly decreases. At least $20 \%$ of SKG mice treated with zymosan develop lung fibrosis, reflected in an increase in lung collagen (hydroxyproline) content at week 10, which increases further until week 16. Treatment of SKG mice with nintedanib in weeks 5-11 after zymosan administration has been shown to attenuate arthritis pathology with no effect on lung fibrosis, while nintedanib treatment in weeks 10-16 led to a reduction in collagen deposition in the lungs. Nintedanib seemed to trigger a slight but selective inflammation in the lung; the impact of this with respect to the fibrosis is unknown [55].

Vascular trigger: vascular lesions, skin, lung and heart fibrosis in Fra- $2^{+/-}$mice

Transgenic overexpression of fos-related antigen-2 (Fra-2) in mice results in development of microvascular disease and pulmonary hypertension. Fra-2 transgenic mice develop progressive fulminant skin fibrosis with dermal thickening, increased hydroxyproline content and an increase in myofibroblasts. Fibrosis in these animals also affects the lung. In this model, treatment with nintedanib from age 9 to 16 weeks effectively attenuated fibrosis in the skin and lung, with a near normalisation of dermal thickness, a reduction in the hydroxyproline content of the skin and lungs, and reduced myofibroblast counts in both organs. Furthermore, nintedanib prominently inhibited pulmonary arterial hypertension-like changes and reduced the proliferation of pulmonary vascular smooth muscle cells, the thickening of vascular walls of pulmonary arteries, and the number of occluded vessels. In the skin, nintedanib reduced apoptosis in dermal microvascular endothelial cells, increased the number of endothelial cells (a marker of vascularisation) and prevented the increase in pro-fibrotic M2 polarised macrophages [39].

\section{Additional animal models}

Experiments in other animal models have demonstrated the activity of nintedanib on fundamental processes of fibrosis. Nintedanib has shown anti-fibrotic activity in mouse models of skin fibrosis [47], radiation-induced lung fibrosis [56], polyhexamethylene guanidine phosphate-induced lung fibrosis [57], renal fibrosis [58], liver fibrosis [59] and muscle fibrosis [60].

\section{Clinical investigation of nintedanib in patients with progressive fibrosing ILDs}

Based on the aforementioned evidence from nonclinical studies that nintedanib inhibits fundamental processes of progressive fibrosis, irrespective of the trigger, and the established efficacy of nintedanib in slowing disease progression in patients with IPF [61, 62], nintedanib has been investigated as a potential treatment for other fibrosing ILDs with a progressive phenotype. The SENSCIS trial (ClinicalTrials.gov identifier NCT02597933) investigated the efficacy and safety of nintedanib versus placebo in patients with SSc-ILD, an extent of fibrotic disease $\geqslant 10 \%$ on high-resolution CT (HRCT) and onset of SSc 7 years before screening [63]. Nintedanib significantly reduced the annual rate of decline in forced vital capacity (FVC) assessed over 52 weeks (primary end-point) ( -52.4 versus $-93.3 \mathrm{~mL} \cdot \mathrm{year}^{-1}$ ). The rate of FVC decline was lower in patients with SSc-ILD in the SENSCIS trial than in patients with IPF in the INPULSIS trials [62], but the relative reduction in the rate of FVC decline observed with nintedanib versus placebo was similar ( $44 \%$ and $49 \%$, respectively). The INBUILD trial (ClinicalTrials.gov identifier NCT02999178) assessed the efficacy and safety of nintedanib $150 \mathrm{mg}$ twice daily versus placebo in patients with a physician-diagnosed ILD other than IPF, who have features of diffuse fibrosing lung disease of $>10 \%$ extent on HRCT [64]. To be eligible to enter the INBUILD trial, patients had to meet criteria for disease progression in the 2 years prior to screening, based on decline in FVC, worsening of respiratory symptoms or an increased extent of fibrotic changes on HRCT. As in the SENSCIS trial, the primary end-point is the annual rate of decline in FVC $\left(\mathrm{mL} \cdot \mathrm{year}^{-1}\right)$ assessed over 52 weeks. There are two co-primary analysis populations: all patients and patients with a usual interstitial pneumonia (UIP)-like fibrotic pattern on HRCT; patients with ILD and a UIP-like pattern on HRCT have been shown in a number of studies to be at greater risk of FVC decline than patients with other patterns on HRCT [5, 10, 65]. The results of the INBUILD trial will be reported in 2019.

\section{Conclusions}

Fibrosing ILDs with a progressive phenotype show commonalities both in clinical behaviour and in the pathogenic mechanisms that drive their progression. Nintedanib is an approved treatment for IPF and has recently been shown to reduce the rate of progression of ILD in patients with SSc-ILD. Data from in vitro and in vivo studies have shown that nintedanib inhibits a number of steps in the initiation and progression of lung fibrosis. Furthermore, nintedanib has demonstrated anti-fibrotic effects in several animal models with features of fibrosing ILDs, irrespective of the trigger that caused the fibrotic lung pathology. A large 
clinical trial of nintedanib in patients with progressive fibrosing ILDs other than IPF will shortly report results.

Acknowledgments: Writing assistance, supported financially by Boehringer Ingelheim, was provided by Wendy Morris (FleishmanHillard Fishburn, London, UK) during the preparation of this article. The authors were fully responsible for all content and editorial decisions, were involved at all stages of manuscript development, and have approved the final version.

Conflict of interest: L. Wollin is an employee of Boehringer Ingelheim Pharma GmbH \& Co. KG. J.H.W. Distler has nothing to disclose. E.F. Redente has nothing to disclose. D.W.H. Riches has nothing to disclose. S. Stowasser is an employee of Boehringer Ingelheim International GmbH. R. Schlenker-Herceg is an employee of Boehringer Ingelheim Pharmaceuticals, Inc. T.M. Maher has, via his institution, received industry-academic funding from GlaxoSmithKline R\&D and UCB; has received consultancy or speakers fees from Apellis, AstraZeneca, Bayer, Biogen Idec, Boehringer Ingelheim, Galapagos, GlaxoSmithKline R\&D, Indalo, Pliant, ProMetic, Roche, Samumed and UCB; and has received consultancy fees from Galecto. M. Kolb reports grants and personal fees for consultancy and lecturing from Roche and Boehringer Ingelheim, grants and personal fees for consultancy from GSK, Gilead and Prometic, grants from Actelion, Respivert, Alkermes and Pharmaxis, personal fees for consultancy from Genoa, Indalo and Third Pole, outside the submitted work.

\section{References}

1 Travis WD, Costabel U, Hansell DM, et al. An official American Thoracic Society/European Respiratory Society statement: update of the international multidisciplinary classification of the idiopathic interstitial pneumonias. Am J Respir Crit Care Med 2013; 188: 733-748.

2 Raghu G, Remy-Jardin M, Myers JL, et al. Diagnosis of idiopathic pulmonary fibrosis. An official ATS/ERS/JRS/ ALAT clinical practice guideline. Am J Respir Crit Care Med 2018; 198: e44-e68.

3 Wells AU, Brown KK, Flaherty KR, et al. What's in a name? That which we call IPF, by any other name would act the same. Eur Respir J 2018; 51: 1800692.

4 Jegal Y, Kim DS, Shim TS, et al. Physiology is a stronger predictor of survival than pathology in fibrotic interstitial pneumonia. Am J Respir Crit Care Med 2005; 171: 639-644.

5 Zamora-Legoff JA, Krause ML, Crowson CS, et al. Progressive decline of lung function in rheumatoid arthritis-associated interstitial lung disease. Arthritis Rheumatol 2017; 69: 542-549.

6 Moore OA, Goh N, Corte T, et al. Extent of disease on high-resolution computed tomography lung is a predictor of decline and mortality in systemic sclerosis-related interstitial lung disease. Rheumatology 2013; 52: 155-160.

7 Fernández Pérez ER, Swigris JJ, Forssén AV, et al. Identifying an inciting antigen is associated with improved survival in patients with chronic hypersensitivity pneumonitis. Chest 2013; 144: 1644-1651.

8 Kirkil G, Lower EE, Baughman RP. Predictors of mortality in pulmonary sarcoidosis. Chest 2018; 153: 105-113.

9 Leung CC, Yu IT, Chen W. Silicosis. Lancet 2012; 379: 2008-2018.

10 Ryerson CJ, Urbania TH, Richeldi L, et al. Prevalence and prognosis of unclassifiable interstitial lung disease. Eur Respir J 2013; 42: 750-757.

11 Cottin V, Wollin L, Fischer A, et al. Fibrosing interstitial lung diseases: knowns and unknowns. Eur Respir Rev 2019; 28: 180100.

12 Maher TM, Wuyts W. Management of fibrosing interstitial lung diseases. Adv Ther 2019; 36: 1518-1531.

13 Strieter RM, Mehrad B. New mechanisms of pulmonary fibrosis. Chest 2009; 136: 1364-1370.

14 Maher TM, Wells AU, Laurent GJ. Idiopathic pulmonary fibrosis: multiple causes and multiple mechanisms? Eur Respir J 2007; 30: 835-839.

15 Altorok N, Wang Y, Kahaleh B. Endothelial dysfunction in systemic sclerosis. Curr Opin Rheumatol 2014; 26: 615-620.

16 Bagnato G, Harari S. Cellular interactions in the pathogenesis of interstitial lung diseases. Eur Respir Rev 2015; 24: $102-114$.

17 Andersson-Sjöland A, de Alba CG, Nihlberg K, et al. Fibrocytes are a potential source of lung fibroblasts in idiopathic pulmonary fibrosis. Int J Biochem Cell Biol 2008; 40: 2129-2140.

18 Willis BC, du Bois RM, Borok Z. Epithelial origin of myofibroblasts during fibrosis in the lung. Proc Am Thorac Soc 2006; 3: 377-382.

19 Hung C, Linn G, Chow YH, et al. Role of lung pericytes and resident fibroblasts in the pathogenesis of pulmonary fibrosis. Am J Respir Crit Care Med 2013; 188: 820-830.

20 Fernandez IE, Eickelberg O. New cellular and molecular mechanisms of lung injury and fibrosis in idiopathic pulmonary fibrosis. Lancet 2012; 380: 680-688.

21 Huang X, Yang N, Fiore VF, et al. Matrix stiffness-induced myofibroblast differentiation is mediated by intrinsic mechanotransduction. Am J Respir Cell Mol Biol 2012; 47: 340-348.

22 Mross K, Stefanic M, Gmehling D, et al. Phase I study of the angiogenesis inhibitor BIBF 1120 in patients with advanced solid tumors. Clin Cancer Res 2010; 16: 311-319.

23 Eisen T, Shparyk Y, Macleod N, et al. Effect of small angiokinase inhibitor nintedanib (BIBF 1120) on QT interval in patients with previously untreated, advanced renal cell cancer in an open-label, phase II study. Invest New Drugs 2013; 31: 1283-1293.

24 Hilberg F, Roth GJ, Krssak M, et al. BIBF 1120: triple angiokinase inhibitor with sustained receptor blockade and good antitumor efficacy. Cancer Res 2008; 68: 4774-4782.

25 Hilberg F, Tontsch-Grunt U, Baum A, et al. Triple angiokinase inhibitor nintedanib directly inhibits tumor cell growth and induces tumor shrinkage via blocking oncogenic receptor tyrosine kinases. J Pharmacol Exp Ther 2018; 364: 494-503.

26 Cope AP, Schulze-Koops H, Aringer M. The central role of T cells in rheumatoid arthritis. Clin Exp Rheumatol 2007; 25: S4-S11.

27 O’Reilly S, Hügle T, van Laar JM. T cells in systemic sclerosis: a reappraisal. Rheumatology 2012; 51: 1540-1549. 
28 Barber EK, Dasgupta JD, Schlossman SF, et al. The CD4 and CD8 antigens are coupled to a protein-tyrosine kinase (p56lck) that phosphorylates the CD3 complex. Proc Natl Acad Sci USA 1989; 86: 3277-3281.

29 Straus DB, Weiss A. Genetic evidence for the involvement of the lck tyrosine kinase in signal transduction through the T cell antigen receptor. Cell 1992; 70: 585-593.

30 Duplay P, Thome M, Hervé F, et al. p56lck interacts via its Src homology 2 domain with the ZAP-70 kinase. J Exp Med 1994; 179: 1163-1172.

31 Weiss A, Littman DR. Signal transduction by lymphocyte antigen receptors. Cell 1994; 76: $263-274$.

32 Wollin L, Ostermann A, Williams C. Nintedanib inhibits pro-fibrotic mediators from $\mathrm{T}$ cells with relevance to connective tissue disease-associated interstitial lung disease. Eur Respir J 2017; 50: Suppl. 61, PA903.

33 Prasse A, Probst C, Bargagli E, et al. Serum CC-chemokine ligand 18 concentration predicts outcome in idiopathic pulmonary fibrosis. Am J Respir Crit Care Med 2009; 179: 717-723.

34 Schupp JC, Binder H, Jäger B, et al. Macrophage activation in acute exacerbation of idiopathic pulmonary fibrosis. PLoS One 2015; 10: e0116775.

35 Hoffmann-Vold AM, Tennøe AH, Garen T, et al. High level of chemokine CCL18 is associated with pulmonary function deterioration, lung fibrosis progression, and reduced survival in systemic sclerosis. Chest 2016; 150: 299-306.

36 van Lieshout AW, Fransen J, Flendrie M, et al. Circulating levels of the chemokine CCL18 but not CXCL16 are elevated and correlate with disease activity in rheumatoid arthritis. Ann Rheum Dis 2007; 66: 1334-1338.

37 Tandon K, Herrmann FE, Ayaub E, et al. Nintedanib attenuates the polarization of profibrotic macrophages through the inhibition of tyrosine phosphorylation on CSF1 receptor. Am J Respir Crit Care Med 2017; 195: A2397.

38 Bellamri N, Morzadec C, Joannes A, et al. Alteration of human macrophage phenotypes by the anti-fibrotic drug nintedanib. Int Immunopharmacol 2019; 72: 112-123.

39 Huang J, Maier C, Zhang Y, et al. Nintedanib inhibits macrophage activation and ameliorates vascular and fibrotic manifestations in the Fra2 mouse model of systemic sclerosis. Ann Rheum Dis 2017; 76: 1941-1948.

40 Maharaj S, Shimbori C, Kolb M. Fibrocytes in pulmonary fibrosis: a brief synopsis. Eur Respir Rev 2013; 22: 552-557.

41 Sato S, Shinohara S, Hayashi S, et al. Anti-fibrotic efficacy of nintedanib in pulmonary fibrosis via the inhibition of fibrocyte activity. Respir Res 2017; 18: 172.

42 Hostettler KE, Zhong J, Papakonstantinou E, et al. Anti-fibrotic effects of nintedanib in lung fibroblasts derived from patients with idiopathic pulmonary fibrosis. Respir Res 2014; 15: 157.

43 Wollin L, Wex E, Pautsch A, et al. Mode of action of nintedanib in the treatment of idiopathic pulmonary fibrosis Eur Respir J 2015; 45: 1434-1445.

44 Schuett J, Ostermann AM, Wollin L. The effect of nintedanib compared to pirfenidone on serum-stimulated proliferation of human primary lung fibroblasts at clinically relevant concentrations. Am J Respir Crit Care Med 2015; 191: A4940.

45 Wollin L, Ostermann A, Wex E, et al. Nintedanib attenuates motility of lung fibroblasts from patients with idiopathic pulmonary fibrosis. Am J Respir Crit Care Med 2014; 189: A2008.

46 Wollin L, Schuett J, Ostermann AM, et al. The effect of nintedanib on platelet derived growth factor-stimulated contraction of human primary lung fibroblasts. Am J Respir Crit Care Med 2016; 193: A2384.

47 Huang J, Beyer C, Palumbo-Zerr K, et al. Nintedanib inhibits fibroblast activation and ameliorates fibrosis in preclinical models of systemic sclerosis. Ann Rheum Dis 2016; 75: 883-890.

48 Wollin L, Maillet I, Quesniaux V, et al. Antifibrotic and anti-inflammatory activity of the tyrosine kinase inhibitor nintedanib in experimental models of lung fibrosis. J Pharmacol Exp Ther 2014; 349: 209-220.

49 Sava P, Ramanathan A, Dobronyi A, et al. Human pericytes adopt myofibroblast properties in the microenvironment of the IPF lung. JCI Insight 2017; 2: e96352.

50 Ebina M, Shimizukawa M, Shibata N, et al. Heterogeneous increase in CD34-positive alveolar capillaries in idiopathic pulmonary fibrosis. Am J Respir Crit Care Med 2004; 169: 1203-1208.

51 Renzoni EA. Neovascularization in idiopathic pulmonary fibrosis: too much or too little? Am J Respir Crit Care Med 2004; 169: 1179-1180.

52 Rol N, de Raaf MA, Sun X, et al. Nintedanib improves cardiac fibrosis but leaves pulmonary vascular remodeling unaltered in experimental pulmonary hypertension. Cardiovasc Res 2019; 115: 432-439.

53 Ackermann M, Kim YO, Wagner WL, et al. Effects of nintedanib on the microvascular architecture in a lung fibrosis model. Angiogenesis 2017; 20: 359-372.

54 Lee HY, Hur J, Kim IK, et al. Effect of nintedanib on airway inflammation and remodeling in a murine chronic asthma model. Exp Lung Res 2017; 43: 187-196.

55 Redente EF, Aguilar MA, Black BP, et al. Nintedanib reduces pulmonary fibrosis in a model of rheumatoid arthritis-associated interstitial lung disease. Am J Physiol Lung Cell Mol Physiol 2018; 314: L998-L1009.

56 De Ruysscher D, Granton PV, Lieuwes NG, et al. Nintedanib reduces radiation-induced microscopic lung fibrosis but this cannot be monitored by CT imaging: a preclinical study with a high precision image-guided irradiator. Radiother Oncol 2017; 124: 482-487.

57 Kim HY, Kim MS, Kim SH, et al. Protective effects of nintedanib against polyhexamethylene guanidine phosphate-induced lung fibrosis in mice. Molecules 2018; 23: E1974.

58 Liu F, Wang L, Qi H, et al. Nintedanib, a triple tyrosine kinase inhibitor, attenuates renal fibrosis in chronic kidney disease. Clin Sci 2017; 131: 2125-2143.

59 Öztürk Akcora B, Storm G, Prakash J, et al. Tyrosine kinase inhibitor BIBF1120 ameliorates inflammation, angiogenesis and fibrosis in $\mathrm{CCl}_{4}$-induced liver fibrogenesis mouse model. Sci Rep 2017; 7: 44545.

60 Piñol-Jurado P, Suárez-Calvet X, Fernández-Simón E, et al. Nintedanib decreases muscle fibrosis and improves muscle function in a murine model of dystrophinopathy. Cell Death Dis 2018; 9: 776.

61 Richeldi L, Costabel U, Selman M, et al. Efficacy of a tyrosine kinase inhibitor in idiopathic pulmonary fibrosis N Engl J Med 2011; 365: 1079-1087.

62 Richeldi L, du Bois RM, Raghu G, et al. Efficacy and safety of nintedanib in idiopathic pulmonary fibrosis. N Engl J Med 2014; 370: 2071-2082. 
63 Distler O, Highland KB, Gahlemann M, et al. Nintedanib for systemic sclerosis-associated interstitial lung disease. N Engl J Med 2019; 380: 2518-2528.

64 Flaherty KR, Brown KK, Wells AU, et al. Design of the PF-ILD trial: a double-blind, randomised, placebo-controlled phase III trial of nintedanib in patients with progressive fibrosing interstitial lung disease. BMJ Open Respir Res 2017; 4: e000212.

65 Oldham JM, Adegunsoye A, Valenzi E, et al. Characterisation of patients with interstitial pneumonia with autoimmune features. Eur Respir J 2016; 47: 1767-1775. 